\title{
Non-invasive early exclusion of chronic thromboembolic pulmonary hypertension after acute pulmonary embolism: the InShape II study
}

\author{
Gudula J A M Boon (1), ' Yvonne M Ende-Verhaar (ㄷ), ${ }^{1}$ Roisin Bavalia (1) , \\ Lahassan H El Bouazzaoui, ${ }^{3}$ Marion Delcroix (1), ${ }^{4}$ Olga Dzikowska-Diduch (1) ,

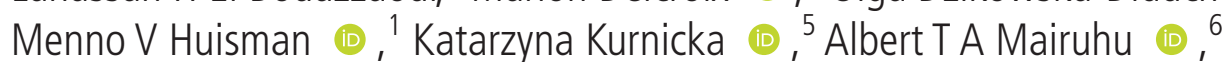

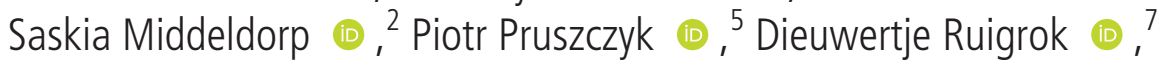 \\ Peter Verhamme (i) , ${ }^{8}$ Hubert W Vliegen 다, ${ }^{9}$ Anton Vonk Noordegraaf (1) , \\ Joris W J Vriend, ${ }^{10}$ Frederikus A Klok (1) , ${ }^{1}$ InShape II study group
}

- Additional material is published online only. To view please visit the journal online (http://dx.doi.org/10.1136/ thoraxjnl-2020-216324).

For numbered affiliations see end of article.

Correspondence to Dr. Frederikus A Klok, Thrombosis and Hemostasis, Leiden Universitair Medisch Centrum, Leiden, Netherlands; f.a.klok@lumc.nl

Received 6 October 2020 Revised 9 February 2021 Accepted 23 February 2021
Check for updates

(C) Author(s) (or their employer(s)) 2021. No commercial re-use. See rights and permissions. Published by BMJ.

\footnotetext{
To cite: Boon GJAM, EndeVerhaar YM, Bavalia R, et al. Thorax Epub ahead of print: [please include Day Month Year]. doi:10.1136/

thoraxjnl-2020-216324
}

\section{ABSTRACT}

Background The current diagnostic delay of chronic thromboembolic pulmonary hypertension (CTEPH) after pulmonary embolism (PE) is unacceptably long, causing loss of quality-adjusted life years and excess mortality. Validated screening strategies for early CTEPH diagnosis are lacking. Echocardiographic screening among all PE survivors is associated with overdiagnosis and costineffectiveness. We aimed to validate a simple screening strategy for excluding CTEPH early after acute PE, limiting the number of performed echocardiograms. Methods In this prospective, international, multicentre management study, consecutive patients were managed according to a screening algorithm starting 3 months after acute PE to determine whether echocardiographic evaluation of pulmonary hypertension $(\mathrm{PH})$ was indicated. If the 'CTEPH prediction score' indicated high pretest probability or matching symptoms were present, the 'CTEPH rule-out criteria' were applied, consisting of ECG reading and $\mathrm{N}$-terminalpro-brain natriuretic peptide. Only if these results could not rule out possible $\mathrm{PH}$, the patients were referred for echocardiography.

Results 424 patients were included. Based on the algorithm, CTEPH was considered absent in 343 $(81 \%)$ patients, leaving 81 patients (19\%) referred for echocardiography. During 2-year follow-up, one patient in whom echocardiography was deemed unnecessary by the algorithm was diagnosed with CTEPH, reflecting an algorithm failure rate of $0.29 \%(95 \% \mathrm{Cl} 0 \%$ to $1.6 \%)$. Overall CTEPH incidence was 3.1\% (13/424), of whom 10 patients were diagnosed within 4 months after the PE presentation.

Conclusions The InShape II algorithm accurately excluded CTEPH, without the need for echocardiography in the overall majority of patients. CTEPH was identified early after acute $\mathrm{PE}$, resulting in a substantially shorter diagnostic delay than in current practice.

\section{INTRODUCTION}

Chronic thromboembolic pulmonary hypertension (CTEPH) is characterised by persistent obstruction of the pulmonary arteries by organised fibrotic thrombi with secondary microvascular remodelling,

\section{Key messages}

What is the key question?

- Since the current unacceptably long diagnostic delay of chronic thromboembolic pulmonary hypertension (CTEPH) after acute pulmonary embolism (PE) leads to decreased quality of life and excess mortality, we aimed to prospectively validate a simple strategy for evaluating the presence of CTEPH early in the course of acute PE.

What is the bottom line?

- The simple non-invasive InShape II algorithm accurately ruled out CTEPH early after acute PE without the need for echocardiography in $81 \%$ of patients with $\mathrm{PE}$, resulting in a substantially faster CTEPH diagnosis than in current routine practice.

Why read on?

- The InShape II study is the first management study to successfully validate a dedicated CTEPH screening strategy after acute PE.

leading to increased pulmonary vascular resistance, pulmonary hypertension $(\mathrm{PH})$, right heart failure and ultimately, if proper and timely treatment is not initiated, death. ${ }^{1-5}$ While this rare disease is the most feared long-term complication of acute pulmonary embolism (PE), its early diagnosis remains an important clinical challenge. ${ }^{67}$ Indeed, the current diagnostic delay of CTEPH after PE is unacceptably long exceeding 1 year, causing loss of quality-adjusted life years and excess mortality. ${ }^{8-11}$

Until recently, there were no clear recommendations for specific follow-up programmes after PE for early detection of CTEPH. ${ }^{12}{ }^{13}$ Subjecting all acute PE survivors to transthoracic echocardiography, which is the recommended screening tool for suspected $\mathrm{PH}$, has been shown to have a low diagnostic yield, results in overdiagnosis and is costineffective. ${ }^{14}$ An active screening algorithm was suggested for the first time in the 2019 Guidelines 


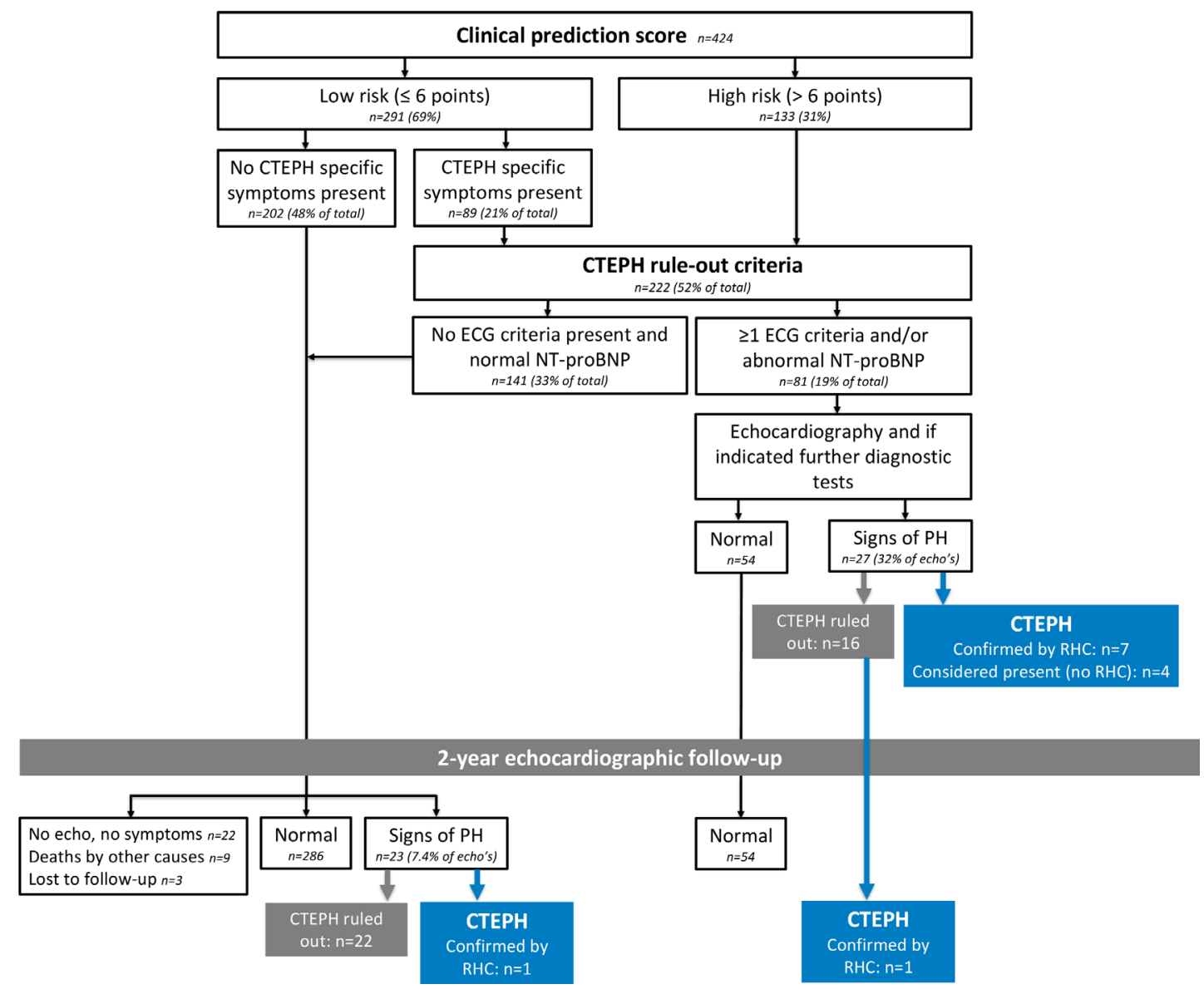

Figure 1 Results of 2-year follow-up after completing the InShape II study algorithm. Note: The ECG criteria of RV pressure overload are as follows: (1) rSR' or rSr' pattern in lead V1, (2) R:S>1 in lead V1 with R>0.5 mV and (3) QRS axis $>90^{\circ}$. 'Signs of PH' relate to echocardiographically determined intermediate or high probability of PH according to the 2015 ESC/ERS guidelines for the diagnosis and treatment of PH. ${ }^{12}$ CTEPH, chronic thromboembolic pulmonary hypertension; NT-proBNP, N-terminal pro-brain natriuretic peptide; $\mathrm{PE}$, pulmonary embolism; $\mathrm{PH}$, pulmonary hypertension; $\mathrm{RHC}$, right heart catheterisation; RV, right ventricle.

on PE of the European Society of Cardiology and the European Respiratory Society (ESC/ERS), and involved the recommendation to apply echocardiography 3-6 months after PE diagnosis in all patients with persistent dyspnoea and/or predisposing conditions for CTEPH. ${ }^{15}$ Given the fact that $50 \%$ of patients with PE report persistent dyspnoea to some degree, a considerable number of patients will require echocardiography according to this guideline, and sufficient resources may not be available around the globe. ${ }^{16-18}$

We have developed a non-invasive screening algorithm aimed at timely exclusion of CTEPH in patients recently diagnosed with PE while limiting the number of required echocardiograms. The stepwise approach of the algorithm starts with application of the 'CTEPH prediction score'. In case this score indicates a high pretest probability of CTEPH, or if symptoms suggestive of CTEPH are present, ECG reading and a N-terminalpro-brain natriuretic peptide (NT-proBNP) assessment are performed as part of the 'CTEPH rule-out criteria' ${ }^{19-21}$ Only if these criteria cannot rule out possible $\mathrm{PH}$, the patients are referred for echocardiography, and further diagnostic testing if necessary. Retrospective evaluation among patients with CTEPH revealed that $91 \%$ of these patients would indeed have been identified correctly and early by the screening algorithm. ${ }^{22}$ In the InShape II study, we aimed to prospectively validate the safety of this algorithm for excluding CTEPH early after acute PE.

\section{METHODS}

\section{Study design and patients}

The InShape II study was a prospective, international, multicentre management study comprising consecutive patients diagnosed with acute PE in five academic hospitals and one teaching hospital in the Netherlands, Belgium and Poland (NCT02555137). All participating hospitals have a dedicated and expert outpatient clinic for PH care. Patients were eligible for inclusion if they (1) were aged 18 years or older; (2) had a CT pulmonary angiography (CTPA) proven diagnosis of first or recurrent symptomatic acute PE; (3) and had been treated with therapeutically dosed anticoagulant therapy for at least 3 months according to current guidelines. Exclusion criteria were known CTEPH or PH, New York Heart Association class III or IV chronic heart failure (echocardiographically confirmed left ventricular systolic or diastolic dysfunction), or severe renal failure (estimated glomerular filtration rate $<15 \mathrm{~mL} / \mathrm{min}$ or renal replacement therapy). Also, patients with medical or psychological conditions not permitting study completion, noncompliance or inability to adhere to treatment or to follow-up visits were excluded. The study protocol was approved by all institutional review boards of the participating hospitals and all patients provided written informed consent before the start of any study procedure. 


\section{Procedures}

\section{Baseline study procedures}

All study participants were managed according to the predefined screening algorithm (figure 1; online supplemental appendix A), initiated during patient's routine visit to the outpatient clinic 3 months after their diagnosis of acute PE. At that time, pretest probability of CTEPH was assessed by calculating the 'CTEPH prediction score' (online supplemental appendix B) and symptoms suggestive of CTEPH were evaluated (i.e. dyspnoea on exertion, oedema, newly developed palpitations, syncope or chest pain). ${ }^{19}$ Only patients with a high pretest probability (>6 points) or those with symptoms that might be associated with CTEPH were subjected to the CTEPH rule-out criteria, that is, assessment of the presence of any of the three ECG criteria of right ventricle (RV) pressure overload, or an abnormal agedependent and gender-dependent NT-proBNP level (online supplemental appendix C). ${ }^{20}$ If at least one of the CTEPH rule-out criteria could not preclude the presence of RV pressure overload according to the judgement of the local investigator, the patients were referred for transthoracic echocardiography, performed according to the 2015 ESC/ERS guidelines on $\mathrm{PH} .^{12}$ As such, the patients were divided into low, intermediate or high echocardiographic probability of PH. CTEPH was considered to be ruled out in patients with low probability of $\mathrm{PH}$. Those with intermediate or high probability of $\mathrm{PH}$ were referred for further diagnostic workup of suspected CTEPH following the standard of care. A diagnosis of CTEPH was established in a CTEPH expertise centre if strict diagnostic criteria, obtained after $\geq 3$ months of adequate therapeutic anticoagulation, were met: (1) $\geq 1$ mismatched segmental perfusion defect demonstrated by ventilation/perfusion scanning; (2) mean pulmonary artery pressure $(\mathrm{mPAP}) \geq 25 \mathrm{~mm} \mathrm{Hg}$ at rest measured by invasive right heart catheterisation (RHC); (3) pulmonary artery wedge pressure $\leq 15 \mathrm{~mm} \mathrm{Hg} .{ }^{12}$ All results were discussed by an independent interdisciplinary working group of $\mathrm{PH}$ specialists to ensure optimal diagnostic management. If CTEPH was confirmed, they received state-of-the-art treatment, preferably pulmonary endarterectomy. Management of confirmed CTEPH was not part of this study protocol.

\section{Study procedures during 2-year follow-up}

All patients without confirmed CTEPH were followed up for 2 years after the index PE diagnosis. During this follow-up period, routine medical care was continued by the treating physician, allowing diagnostic tests if deemed necessary. At 2 years, the patients were subjected to a follow-up echocardiography to evaluate the presence of CTEPH. As with the baseline echocardiogram, further CTEPH-targeted diagnostic tests were performed in case of intermediate or high probability of $\mathrm{PH}$.

\section{Objectives}

The primary objective was to determine the failure rate of the screening algorithm, defined as the 2-year incidence of confirmed CTEPH in patients with PE in whom echocardiography was deemed unnecessary by the algorithm at baseline. Main secondary objectives of the study were to evaluate (1) the incidence of CTEPH in the studied population; and (2) the feasibility of the screening algorithm (i.e. both the number of necessary echocardiograms at baseline and their results including false positive and incidental findings). A false-positive echocardiogram was defined as indicating intermediate or high probability of $\mathrm{PH}$, which was not confirmed on RHC.

\section{Statistical analysis}

The sample size calculation was based on the assumption that the point estimate of the incidence of CTEPH 2 years after the diagnosis of acute PE in patients that do not need referral for echocardiography according to the screening algorithm is $\leq 1.0 \%$, which represents a sensitivity $\geq 92 \%$ assuming a $4.0 \%$ CTEPH incidence. ${ }^{623}$ Accordingly, we determined that a sample of 268 patients would provide $80 \%$ power to reject the null hypothesis, that is, that the point estimate of the CTEPH rate in those patients would be $>1.0 \%$, at an overall one-sided significance level of 0.05 . Assuming that echocardiography would be avoided in $75 \%$ of patients by the screening algorithm, and taking a 5\% loss to follow-up into account, we aimed to include 375 patients.

Baseline characteristics are described as mean with SD or median with IQR. The diagnostic failure rate of the algorithm and the incidence of CTEPH was calculated with corresponding 95\% CI. Feasibility was predetermined to be accomplished if $30 \%$ of patients or less would require referral for echocardiography, which is the conservative estimation of the required number of echocardiograms necessary if performed in all patients with persistent symptoms. ${ }^{162425}$ All statistical tests were performed using SPSS Statistics software (V.25.0, IBM).

\section{RESULTS \\ Study patients}

From February 2016 to October 2017, a total of 424 consecutive patients with a diagnosis of acute PE were included in six hospitals in the Netherlands, Belgium and Poland after excluding 162 patients $(26 \%)$ for various reasons, in line with the predefined exclusion criteria (online supplemental appendix D). The baseline characteristics of the study patients are summarised in table 1: 49\% was male, mean age was 56 years (SD 16) and 19\% had a history of venous thromboembolism (VTE).

\section{Baseline study procedures}

The algorithm was started at a mean of 4.3 months (SD 1.9) after the index PE diagnosis. CTEPH was considered absent in 343 out of 424 patients (81\%) without performing echocardiography. This was based on both a low CTEPH prediction score ( $\leq 6$ points) and the absence of symptoms in 202 patients $(48 \%$ of total), and because the rule-out criteria did not indicate presence of $\mathrm{PH}$ in 141 of the 222 remaining patients (33\% of total; figure 1). Hence, 81 patients (19\% of total) were referred for echocardiography at baseline.

\section{Follow-up study procedures}

Of the 343 patients in whom CTEPH was considered absent according to the algorithm, one patient was diagnosed with CTEPH 11 months after the PE diagnosis, for a diagnostic failure rate of $0.29 \%$ (95\% CI $0.05 \%$ to $1.6 \%$ ). This patient with persistent dyspnoea had no relevant medical history and a CTEPH prediction score of 3 points (table 2: patient number 13). The CTEPH rule-out criteria precluded the possibility of PH. Echocardiography was eventually performed 6 months after the PE diagnosis because of persistent dyspnoea. A normal peak tricuspid regurgitation gradient (TRPG; $26 \mathrm{~mm} \mathrm{Hg}$ ) was found, accompanied by borderline values of inferior vena cava diameter $(21 \mathrm{~mm}$ with normal collapse at inspiration, normal $<22 \mathrm{~mm})$ and end-systolic right atrial area $\left(18 \mathrm{~cm}^{2}\right.$, normal $<19 \mathrm{~cm}^{2}$ ), consistent with a 'low probability of $\mathrm{PH}$ ' classification. The patient's progressive exertional dyspnoea over time however initiated further diagnostic tests, upon which ultimately a ventilation/perfusion (V/Q) scan performed 2 months after the 


\begin{tabular}{lc}
\hline \multicolumn{1}{l}{ Table 1} & Baseline characteristics of the included patients \\
\hline & $56(16)$ \\
\hline Age (years, mean \pm SD) & $208(49)$ \\
\hline Male gender $(\mathrm{n}, \%)$ & $28(5.8)$ \\
\hline BMI $\left(\mathrm{kg} / \mathrm{m}^{2}\right)$, mean \pm SD & $246(58)$ \\
\hline Unprovoked PE $(\mathrm{n}, \%)$ & $9(2.2)$ \\
\hline High-risk PE $(\mathrm{n}, \%)$ & $82(19)$ \\
\hline Previous VTE $(\mathrm{n}, \%)$ & \\
\hline Comorbidities $(\mathrm{n}, \%)$ & $74(18)$ \\
\hline Anaemia & $48(11)$ \\
\hline COPD/asthma & $33(7.8)$ \\
\hline Active malignancy & $32(7.6)$ \\
\hline Diabetes mellitus & $25(5.9)$ \\
\hline Coronary artery disease & $20(4.7)$ \\
\hline Rheumatic disease & $19(4.5)$ \\
\hline Hypothyroidism & $5(1.2)$ \\
\hline Interstitial lung disease & $4(0.9)$ \\
\hline Inflammatory bowel disease & $3(0.7)$ \\
\hline Known antiphospholipid antibodies & $2(0.5)$ \\
\hline Major vasculitis syndromes & $1(0.2)$ \\
\hline Prior infected pacemaker leads & $1(0.2)$ \\
\hline Splenectomy & $302(71)$ \\
\hline Anticoagulant treatment at 3-month follow-up visit $(\mathrm{n}, \%)$ \\
\hline DOAC & $100(24)$ \\
\hline VKA & $35(8.3)$ \\
\hline LMWH & \\
\hline A & \\
\hline
\end{tabular}

Active malignancy was defined as diagnosis of cancer within 6 months prior to enrolment, any treatment for cancer within the previous 6 months or recurrent metastatic cancer. Rheumatic disease was defined as known rheumatic arthritis, osteoarthritis, connective tissue disease, systemic lupus erythematosus, ankylosing spondylitis or Sjögren syndrome. Anaemia was defined as: males $<8.5 \mathrm{mmol} / \mathrm{L}$ or $<13.5 \mathrm{~g} / \mathrm{dL}$; females $<7.5 \mathrm{mmol} / \mathrm{L}$ or $<12.0$ $\mathrm{g} / \mathrm{dL}$.

$\mathrm{BMI}$, body mass index; DOAC, direct oral anticoagulant: $\mathrm{LMWH}$, low-molecularweight heparin; $\mathrm{PE}$, pulmonary embolism; VKA, vitamin $\mathrm{K}$ antagonist; VTE, venous thromboembolism.

echocardiography showed persistent bilateral perfusion defects in five lung segments. RHC confirmed CTEPH, although with a slightly elevated mPAP of $26 \mathrm{~mm} \mathrm{Hg}$. Notably, the pulmonary vascular resistance (PVR) was normal $\left(133\right.$ dynes $\left.\cdot \mathrm{s} \cdot \mathrm{cm}^{-5}\right)$ as were cardiac index $\left(3.7 \mathrm{~L} / \mathrm{min} / \mathrm{m}^{2}\right)$ and wedge pressure $(13 \mathrm{~mm} \mathrm{Hg})$.

Of all patients in whom CTEPH was considered absent at baseline, echocardiography with or without V/Q scan and RHC ruled out CTEPH in 308 patients at the 2-year follow-up visit. Nine patients died of other causes than CTEPH before the scheduled follow-up echocardiography could be performed (9/424, 2.1\%; online supplemental appendix E), and echocardiography was not performed in 22 patients $(22 / 424,5.2 \%)$ for various reasons (Appendix F). None of these latter 22 patients had reported symptoms suggestive of CTEPH during the 2-year follow-up visit. Three patients were lost to follow-up (3/424, $0.71 \%$ ). Recurrent VTE was diagnosed in 14 patients during follow-up; CTEPH was ruled out by echocardiography at the 2-year follow-up visit in all of them.

\section{Secondary outcomes}

Of the 81 patients with echocardiography performed at baseline, $27(33 \%)$ had findings consistent with intermediate or high probability of $\mathrm{PH}$. Of these, CTEPH was ruled out in 16 patients by normal RHC. CTEPH was confirmed by RHC soon after echocardiography in seven patients. In four patients, CTEPH was considered present even though an RHC could not be performed due to severe comorbidities (figure 1, table 3).

In addition to the 11 patients with CTEPH diagnosed at baseline and the patient missed by the algorithm, one more patient developed CTEPH. At baseline, the patient had an abnormal echocardiogram and V/Q scan but a normal RHC (mPAP $19 \mathrm{~mm} \mathrm{Hg}$ and PVR 190 dynes $\cdot \mathrm{s}^{\cdot} \mathrm{cm}^{-5}$ ) which proved to have progressed to CTEPH 2 years later (mPAP $33 \mathrm{~mm} \mathrm{Hg}$ and PVR 242 dynes $\cdot \mathrm{s} \cdot \mathrm{cm}^{-5}$ ). Altogether, CTEPH was confirmed or considered present in 13 patients (table 2). This accumulates to a $3.1 \%$ (95\% CI $1.8 \%$ to $5.2 \%$ ) 2-year incidence of CTEPH. CTEPH was diagnosed within 4 months after the index PE diagnosis in 10 of 13 patients (77\%).

The predetermined definition of 'feasibility' of the screening algorithm was met since $19 \%$ of patients were referred for echocardiography. At baseline, 16 (20\%) of all performed echocardiograms were judged false positive after RHC. Two patients $(2.5 \%)$ had incidental findings (patent ductus arteriosus and diastolic dysfunction) without therapeutic consequences. During the follow-up study procedures, echocardiography was false positive in 22 patients $(7.1 \%$ of all performed echocardiograms). Twelve patients $(3.9 \%)$ had incidental findings: atrial fibrillation $(n=1)$, dilated aorta $(n=7)$, hypertrophic cardiomyopathy $(n=1)$, dilated left atrium $(n=2)$ and diastolic dysfunction $(n=1)$. We did not find any differences in the performance of the InShape II algorithm between men and women.

\section{DISCUSSION}

The InShape II study was a prospective international single-arm management study in which we demonstrated that our simple, non-invasive screening algorithm accurately and early excluded CTEPH after acute PE, while avoiding echocardiography in $81 \%$ of patients. Importantly, the vast majority of patients developing CTEPH were diagnosed within 4 months after the index PE diagnosis, which is substantially earlier than the 12-24 months diagnostic delay reported from the current clinical practice. ${ }^{9} 11$ The InShape II study is the first management study to successfully validate a dedicated CTEPH screening tool among patients with PE.

Only one patient (failure rate $0.29 \%$ ) was missed by the algorithm; echocardiography had not been performed because the CTEPH rule-out criteria did not identify signs of $\mathrm{PH}$. Although the mPAP was abnormal $(26 \mathrm{mmHg}$, normal $<25 \mathrm{~mm} \mathrm{Hg}$, meeting the criteria for CTEPH, the PVR was within normal limits (133 dynes $\cdot \mathrm{s} \cdot \mathrm{cm}^{-5}$, normal $<240$ dynes $\cdot \mathrm{s} \cdot \mathrm{cm}^{-5}$ ) which excludes pulmonary arterial hypertension. It is therefore questionable whether this patient actually had CTEPH. Earlier studies have indeed demonstrated that the rule-out criteria had a 90\%-95\% sensitivity for early stage (or mild) CTEPH, in comparison with a $100 \%$ sensitivity for more severe CTEPH. ${ }^{20} 22$ This lower sensitivity for early stage CTEPH is presumably explained by the initial adaptation of the right ventricle to increased RV afterload by enhancing its contractility and thickening the RV muscle wall ('coupling'). Since RV dilatation mostly occurs in late stages of pressure overload ('uncoupling'), as does hypertrophy, the ECG and biomarkers of myocyte stress may remain normal in the early stages of disease. As such, echocardiography may not be a sensitive parameter to identify an early disease state either, as was the case in this patient in whom echocardiography 2 months before the final CTEPH diagnosis indicated low risk of $\mathrm{PH}^{26}$ Of note, two other CTEPH cases also had a normal PVR and therefore do not meet the current criteria of the updated $\mathrm{PH}$ 


\begin{tabular}{|c|c|c|c|c|c|c|c|c|}
\hline Baseline & & Follow-up & & & & & & $\begin{array}{l}\text { Adjudication } \\
\text { and timing } \\
\text { of CTEPH } \\
\text { diagnosis } \\
\text { (in months } \\
\text { after index PE } \\
\text { diagnosis) }\end{array}$ \\
\hline & $\begin{array}{l}\text { Chronic thrombi } \\
\text { and/or signs of } \\
\text { PH present at } \\
\text { index CTPA }\end{array}$ & $\begin{array}{l}\text { Symptoms } \\
\text { suggestive of } \\
\text { CTEPH present }\end{array}$ & $\begin{array}{l}\text { CTEPH prediction } \\
\text { score }\end{array}$ & $\begin{array}{l}\text { CTEPH rule-out } \\
\text { criteria }\end{array}$ & $\begin{array}{l}\text { Echocardiography } \\
\text { results* }\end{array}$ & $\begin{array}{l}\text { Results of immediate } \\
\text { further diagnostic } \\
\text { workup }\end{array}$ & $\begin{array}{l}\text { Results and timing of repeat } \\
\text { testing (in months after index } \\
\text { PE diagnosis) }\end{array}$ & \\
\hline No 1 & Yes & Yes & 11 & $\begin{array}{l}\text { NT-proBNP } \\
\text { elevated, } 1 \text { ECG } \\
\text { criterium }\end{array}$ & $\begin{array}{l}\text { High probability of PH: } \\
\text { TRPG } 57\end{array}$ & $\begin{array}{l}\text { V/Q: multiple } \\
\text { perfusion defects } \\
\text { Pulmonary } \\
\text { angiography: } \\
\text { multiple chronic } \\
\text { thrombi- RHC: mPAP } \\
\text { 32, wedge } 8, \text { CO } \\
\text { 4.0, PVR } 840\end{array}$ & N.A. & $\begin{array}{l}\text { CTEPH confirmed } \\
\text { by RHC after } 4 \\
\text { months }\end{array}$ \\
\hline No 2 & Yes & Yes & 11 & 1 ECG criterium & $\begin{array}{l}\text { Intermediate } \\
\text { probability of PH: } \\
\text { TRPG } 40\end{array}$ & $\begin{array}{l}\text { V/Q: multiple } \\
\text { perfusion defects } \\
\text { Pulmonary } \\
\text { angiography: } \\
\text { multiple chronic } \\
\text { thrombi } \\
\text { RHC: mPAP 33, } \\
\text { wedge 10, CO 7.8, } \\
\text { PVR } 235\end{array}$ & N.A. & $\begin{array}{l}\text { CTEPH confirmed } \\
\text { by RHC after } 4 \\
\text { months }\end{array}$ \\
\hline No 3 & Yes & Yes & 11 & 1 ECG criterium & $\begin{array}{l}\text { Intermediate } \\
\text { probability of PH: } \\
\text { TRPG 35, secondary } \\
\text { signs of PH }\end{array}$ & $\begin{array}{l}\text { CTPA with perfusion } \\
\text { images: multiple } \\
\text { perfusion defects } \\
\text { RHC: mPAP 30, } \\
\text { wedge 8, CO 8.1, } \\
\text { PVR } 193\end{array}$ & $N . A$. & $\begin{array}{l}\text { CTEPH confirmed } \\
\text { by RHC after } 14 \\
\text { months }\end{array}$ \\
\hline No 4 & Yes & Yes & 11 & 1 ECG criterium & $\begin{array}{l}\text { Intermediate } \\
\text { probability of PH: } \\
\text { TRPG 35, secondary } \\
\text { signs of PH }\end{array}$ & $\begin{array}{l}\text { RHC: } \mathrm{mPAP} 34, \\
\text { wedge 12, CO 4.3, } \\
\text { PVR } 419\end{array}$ & N.A. & $\begin{array}{l}\text { CTEPH confirmed } \\
\text { by RHC after } 4 \\
\text { months }\end{array}$ \\
\hline No 5 & Yes & No & 8 & $1 \mathrm{ECG}$ criterium & $\begin{array}{l}\text { High probability of } \mathrm{PH} \text { : } \\
\text { TRPG } 85 \text {, secondary } \\
\text { signs of } \mathrm{PH} \text {, patent } \\
\text { ductus arteriosus }\end{array}$ & $\begin{array}{l}\text { CTPA: chronic } \\
\text { thrombi } \\
\text { V/Q: no clear } \\
\text { perfusion defects } \\
\text { RHC: mPAP 46, } \\
\text { wedge } 12, \text { CO 5.5, } \\
\text { PVR } 496\end{array}$ & $N . A$. & $\begin{array}{l}\text { CTEPH confirmed } \\
\text { by RHC after } 4 \\
\text { months }\end{array}$ \\
\hline No 6 & Yes & Yes & 2 & $\begin{array}{l}\text { Elevated NT- } \\
\text { proBNP }\end{array}$ & $\begin{array}{l}\text { High probability of PH: } \\
\text { TRPG 55, secondary } \\
\text { signs of PH }\end{array}$ & $\begin{array}{l}\text { CTPA: chronic } \\
\text { thrombi } \\
\text { RHC: mPAP 29, } \\
\text { wedge 11, C0 5.6, } \\
\text { PVR } 255\end{array}$ & N.A. & $\begin{array}{l}\text { CTEPH confirmed } \\
\text { by RHC after } 4 \\
\text { months }\end{array}$ \\
\hline No 7 & Yes & Yes & 11 & $\begin{array}{l}\text { Elevated NT- } \\
\text { proBNP }\end{array}$ & $\begin{array}{l}\text { Intermediate } \\
\text { probability of PH: } \\
\text { TRPG } 35\end{array}$ & $\begin{array}{l}\text { Pulmonary } \\
\text { angiography: } \\
\text { multiple chronic } \\
\text { thrombi, decreased } \\
\text { flow } \\
\text { RHC: mPAP 32, } \\
\text { wedge 14, CO 5.4, } \\
\text { PVR } 317\end{array}$ & N.A. & $\begin{array}{l}\text { CTEPH confirmed } \\
\text { by RHC after } 4 \\
\text { months }\end{array}$ \\
\hline No 8 & Yes & Yes & 9 & $\begin{array}{l}\text { Elevated NT- } \\
\text { proBNP, } 1 \text { ECG } \\
\text { criterium }\end{array}$ & $\begin{array}{l}\text { High probability of PH: } \\
\text { TRPG } 80 \text {, secondary } \\
\text { signs of PH }\end{array}$ & $\begin{aligned} & \text { CTPA: chronic } \\
& \text { thrombi } \\
& \text { RHC not performed }\end{aligned}$ & N.A. & $\begin{array}{l}\text { CTEPH } \\
\text { considered } \\
\text { presentt after } 3 \\
\text { months }\end{array}$ \\
\hline No 9 & No & Yes & 2 & $\begin{array}{l}\text { Elevated NT- } \\
\text { proBNP }\end{array}$ & $\begin{array}{l}\text { Intermediate } \\
\text { probability of PH: } \\
\text { TRPG 35, secondary } \\
\text { signs of PH }\end{array}$ & Not performed & $N . A$. & $\begin{array}{l}\text { CTEPH } \\
\text { considered } \\
\text { present† after } 3 \\
\text { months }\end{array}$ \\
\hline No 10 & No & Yes & 5 & $\begin{array}{l}\text { Elevated NT- } \\
\text { proBNP, } 1 \text { ECG } \\
\text { criterium }\end{array}$ & $\begin{array}{l}\text { Intermediate } \\
\text { probability of PH: } \\
\text { TRPG not measurable, } \\
\text { secondary signs of PH }\end{array}$ & Not performed & N.A. & $\begin{array}{l}\text { CTEPH } \\
\text { considered } \\
\text { present† after } 4 \\
\text { months }\end{array}$ \\
\hline
\end{tabular}


Table 2 Continued

\begin{tabular}{|c|c|c|c|c|c|c|c|c|c|}
\hline No 11 & Yes & No & 8 & 3 ECG criteria & $\begin{array}{l}\text { Intermediate } \\
\text { probability of PH: } \\
\text { TRPG 38, secondary } \\
\text { signs of PH }\end{array}$ & $\begin{array}{l}\text { CTPA: chronic } \\
\text { thrombi and signs } \\
\text { of PH } \\
\text { RHC: } m \text { PAP 19, } \\
\text { wedge 4, CO 6.3, } \\
\text { PVR } 190\end{array}$ & $\begin{array}{l}\triangleright \\
\triangleright\end{array}$ & $\begin{array}{l}\text { Echo at } 20 \text { months; } \\
\text { intermediate probability } \\
\text { of PH: TRPG 45, secondary } \\
\text { signs of PH } \\
\text { CTPA: increase in chronic } \\
\text { thrombi and signs of PH } \\
\text { RHC: mPAP 33, wedge 13, } \\
\text { CO 6.6, PVR } 242\end{array}$ & $\begin{array}{l}\text { CTEPH confirmed } \\
\text { by RHC after } 26 \\
\text { months }\end{array}$ \\
\hline No 12 & Unknown & Yes & 8 & $\begin{array}{l}\text { Elevated NT- } \\
\text { proBNP, } 1 \text { ECG } \\
\text { criterium }\end{array}$ & $\begin{array}{l}\text { Intermediate } \\
\text { probability of PH: } \\
\text { TRPG 26, secondary } \\
\text { signs of PH }\end{array}$ & $\begin{array}{l}\text { V/Q: multiple } \\
\text { perfusion defects } \\
\text { (additional imaging tests } \\
\text { and RHC were refused) }\end{array}$ & $>$ & $\begin{array}{l}\text { Echo at } 39 \text { months; high } \\
\text { probability of PH: TRPG } \\
55 \text {, secondary signs of PH }\end{array}$ & $\begin{array}{l}\text { CTEPH } \\
\text { considered } \\
\text { presentt after } 4 \\
\text { months }\end{array}$ \\
\hline No 13 & Yes & Yes & 3 & None & N.A. & - & 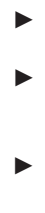 & $\begin{array}{l}\text { Echo at } 6 \text { months; low } \\
\text { probability of PH: TRPG } 26 \\
\text { CTPA with perfusion } \\
\text { images: multiple perfusion } \\
\text { defects } \\
\text { RHC: mPAP } 26 \text {, wedge } 13 \text {, } \\
\text { CO } 7.2 \text {, PVR } 133\end{array}$ & $\begin{array}{l}\text { CTEPH confirmed } \\
\text { by RHC after } 11 \\
\text { months }\end{array}$ \\
\hline
\end{tabular}

*Secondary echocardiographic signs suggesting PH used to assess the probability of PH in addition to tricuspid regurgitation velocity measurements in the 2015 ESC/ERS guidelines for the diagnosis and treatment of PH. Those relate to right ventricle/left ventricle basal diameter ratio $>1.0$, flattening of the interventricular septum (left ventricular eccentricity index $>1.1$ in systole and/ or diastole), right ventricular outflow Doppler acceleration time $<105 \mathrm{~ms}$ and/or midsystolic notching, early diastolic pulmonary regurgitation velocity $>2.2 \mathrm{~m} / \mathrm{s}$, pulmonary artery diameter $>25$ $\mathrm{mm}$, inferior cava diameter $>21 \mathrm{~mm}$ with decreased inspiratory collapse $\left(<50 \%\right.$ with a sniff or $<20 \%$ with quiet inspiration), right atrial area (end-systole) $>18 \mathrm{~cm}{ }^{2} .2$

tThese patients are considered to very likely have CTEPH despite not performing an RHC because of several reasons that are described in detail in table 3

$\mathrm{CO}$, cardiac output (displayed in L/min); CTEPH, chronic thromboembolic pulmonary hypertension; CTPA, CT pulmonary angiography; IVC, inferior vena cava; mPAP, mean pulmonary artery pressure (displayed in mm Hg); N.A., not applicable; NT-proBNP, N-terminal pro-brain natriuretic peptide; PA, pulmonary artery; PE, pulmonary embolism; PH, pulmonary hypertension; PVR, pulmonary vascular resistance (displayed in dynes $\cdot \mathrm{s} \cdot \mathrm{cm}^{-5}$ ); RA, right atrium; RHC, right heart catheterisation; RV, right ventricle; TRPG, tricuspid regurgitation peak gradient (displayed in mm Hg); V/Q, ventilation/perfusion scan.

definition incorporating an elevated PVR. Even so, according to the guidelines valid at the time of our study and applied in the historical literature on CTEPH to which we compare our findings, the diagnosis was correct. One could argue that the evolving definition of $\mathrm{PH}$ from an mPAP of $25-20 \mathrm{~mm} \mathrm{Hg}$ may further increase the number of missed cases by both the InShape II algorithm and the routine use of echocardiography. ${ }^{27}$ This remains to be evaluated in future studies.

The overall CTEPH incidence in our cohort was estimated to be $3.1 \%$ (95\% CI $1.8 \%$ to $5.2 \%$ ), which is in line with historical literature (3.2\% in PE survivors), providing external validity to our study. ${ }^{6}$ Importantly, RHC had not been performed in four cases due to clinical circumstances. For the sake of the study, we have considered these patients to have CTEPH anyway to make sure our definition of the primary outcome was as sensitive as possible. It has been argued that CTEPH may be a prevalent rather than an incident diagnosis among patients with acute PE. The main argument for this hypothesis comes from two studies demonstrating that typical radiological CTEPH characteristics often were present on the index CTPA performed to diagnose acute PE in patients diagnosed with CTEPH during follow-up. ${ }^{428-31}$ Our study adds to this discussion by demonstrating that CTEPH may be either an incident or a prevalent disease in the clinical course of acute PE. In total, 10 of 13 patients with CTEPH were diagnosed early after their PE diagnosis and 8 of

Table 3 Details of patients considered to have CTEPH in whom RHC was not performed despite abnormal baseline echocardiogram

\begin{tabular}{|c|c|c|c|c|}
\hline & Medical history & Result of baseline echocardiography* & Additional imaging results & Reason for not performing $\mathrm{RHC}$ \\
\hline No 1 & $\begin{array}{l}\text { COPD GOLD IV with use of oxygen } \\
\text { therapy with severe functional } \\
\text { limitations }\end{array}$ & $\begin{array}{l}\text { High probability of } \mathrm{PH} \text { : } \\
\text { TRPG } 80 \text {, secondary signs of } \mathrm{PH}\end{array}$ & $\begin{array}{l}\text { CTPA: multiple signs of RV pressure } \\
\text { overload, chronic thrombi and severe } \\
\text { emphysema }\end{array}$ & $\begin{array}{l}\text { Died of progressive respiratory failure } \\
\text { presumably due to CTEPH within } 1 \text { year } \\
\text { after PE }\end{array}$ \\
\hline No 2 & $\begin{array}{l}\text { Sarcoma with chemotherapy } \\
\text { treatment }\end{array}$ & $\begin{array}{l}\text { High probability of } \mathrm{PH} \text { : } \\
\text { TRPG } 35 \text {, secondary signs of } \mathrm{PH}\end{array}$ & $\begin{array}{l}\text { N.A. (refrained from further diagnostic } \\
\text { workup or treatment because of progressive } \\
\text { sarcoma) }\end{array}$ & $\begin{array}{l}\text { Died of advanced sarcoma, } 1.5 \text { years after } \\
\text { the index PE }\end{array}$ \\
\hline No 3 & Ischaemic cardiomyopathy & $\begin{array}{l}\text { Intermediate probability of PH: } \\
\text { TRPG not measurable, sSecondary signs } \\
\text { of PH }\end{array}$ & $\begin{array}{l}\text { N.A. (further diagnostic workup was } \\
\text { planned but declined after a carcinoma of } \\
\text { unknown primary origin was diagnosed) }\end{array}$ & $\begin{array}{l}\text { Died of carcinoma of unknown primary } \\
\text { origin within } 1.5 \text { years after the PE }\end{array}$ \\
\hline No 4 & Atrial fibrillation, hypertension & $\begin{array}{l}\text { Intermediate probability of PH: } \\
\text { TRPG 26, secondary signs of PH: RA }\end{array}$ & $\begin{array}{l}\text { V/Q: multiple perfusion defects } \\
\text { Echo at } 39 \text { months; high probability } \\
\text { of PH: TRPG 55, secondary signs of PH: } \\
\text { RV, RA and PA }\end{array}$ & $\begin{array}{l}\text { Patient refrained from RHC despite increase } \\
\text { in TRPG and progressive exertional dyspnoea }\end{array}$ \\
\hline
\end{tabular}

*Secondary echocardiographic signs suggesting PH used to assess the probability of PH in addition to tricuspid regurgitation velocity measurements in the 2015 ESC/ERS guidelines for the diagnosis and treatment of $\mathrm{PH}$. Thoserelate to: right ventricle/left ventricle basal diameter ratio $>1.0$, flattening of the interventricular septum (left ventricular eccentricity index $>1.1$ in systole and/ or diastole), right ventricular outflow doppleracceleration time $<105 \mathrm{msec}$ and/or midsystolic notching, early diastolic pulmonaryregurgitation velocity $>2.2 \mathrm{~m} / \mathrm{sec}$, pulmonary artery diameter $>25$ $\mathrm{mm}$, inferior cava diameter $>21 \mathrm{~mm}$ with decreased inspiratory collapse ( $<50 \%$ with a sniff or $<20 \%$ with quiet inspiration), Right atrial area(end-systole) $>18 \mathrm{~cm}^{2}{ }^{12}$

CTEPH, chronic thromboembolic pulmonary hypertension; CTPA, CT pulmonary angiography; GOLD, Global Initiative for Obstructive Lung Disease Criteria for COPD; N.A., not applicable; PA, pulmonary artery; PE, pulmonary embolism; PH, pulmonary hypertension; RHC, right heart catheterisation; RV, right ventricle; TRPG, tricuspid regurgitation peak gradient. 
them had signs of CTEPH on the index CTPA, which is suggestive of CTEPH appearing in disguise of acute PE. Still, CTEPH had clearly developed over time in at least one patient (table 2). This emphasises the importance of remaining vigilant for CTEPH if new-onset dyspnoea develops in the early years after an acute PE diagnosis, independent of diagnostic tests shortly after the PE.

Although the results of this study support the use of the CTEPH prediction score, we acknowledge that the score itself has limitations inherent to its derivation. ${ }^{19}$ Because the study population used to construct the score included a limited number of patients with proven CTEPH, variables not considered causally related to CTEPH emerged as predictors-and thus score variables—notably diabetes and thrombolysis. Considering the absence of other validated methods to assess pretest probability of CTEPH in patients with $\mathrm{PE}$, this score nonetheless remains the best studied tool. A straightforward way to improve the accuracy of the CTEPH prediction score would be substituting the current CTPA RV/LV ratio assessment with more extensive CTPA evaluation for signs of CTEPH. Of note, two patients diagnosed with CTEPH at baseline had no symptoms, but were 'detected' by the score. This underlines the strength of combining a symptom-based with a pretest probability-based assessment in this setting and supports the $2019 \mathrm{ESC} / \mathrm{ERS}$ guideline recommendations to apply a CTEPH screening algorithm based on symptoms combined with estimation of the pretest probability in all PE survivors. ${ }^{15}$

What are the clinical implications of our findings? Our study shows that dedicated follow-up of PE leads to early detection of CTEPH, which is by itself associated with better prognosis. ${ }^{10}{ }^{15} \mathrm{We}$ provide an alternative to (but do not suggest to replace) the follow-up algorithm as proposed by the guideline which can be easily applied in several healthcare settings, including primary care. Notably, even though only $19 \%$ of patients was subjected to echocardiography at baseline, we still observed a considerable rate of false-positive test results and incidental findings, emphasising the potential overdiagnosis when echocardiography would be used as first-line screening test. This is in line with a large meta-analysis including 27 studies that performed both echocardiography and RHC, in which a suboptimal specificity of $74 \%(95 \%$ CI $64 \%$ to $81 \%)$ was found. ${ }^{32}$ The associated considerable number of false-positive test results necessitates performing additional-frequently expensive and invasive- diagnostic tests that might be avoided by applying the strategy evaluated in the current study. Of note, our algorithm was aimed at excluding CTEPH early after the PE diagnosis with optimal use of healthcare resources, but not at explaining symptoms of incomplete recovery after $\mathrm{PE}^{33}$ Importantly, echocardiography remains the diagnostic test of choice in patients with clinically suspected $\mathrm{PH}$. Further, even if our algorithm indicates absence of CTEPH given normal rule-out criteria, echocardiography may still be indicated in symptomatic patients to evaluate the presence of other heart disease. In particular, evaluating the presence of chronic thromboembolic pulmonary disease (CTEPD) is relevant in patients with persistent dyspnoea in the course of PE, but was not covered by the algorithm. Importantly, we only focused on CTEPH and not on CTEPD since (1) delay in diagnosing CTEPH is associated with poor outcome while this has never been shown for CTEPD, and (2) 'screening' for CTEPD would involve pulmonary imaging in all symptomatic cases as well as considerable expertise that cannot be captured in a simple algorithm applicable to a wide range of healthcare settings.

Strengths of our study include the prospective design, the large study population, near complete follow-up and adjudication of suspected endpoints by expert PH teams. Performing the study across several European countries and hospital settings, using different NT-proBNP assays and reading the ECG locally after simple instruction all support external validity of our results and the wide applicability of the algorithm. Good interobserver agreement for the assessment of the prediction score and the rule-out criteria have been demonstrated in earlier studies. ${ }^{19} 2122$ Some limitations need to be mentioned as well, in particular the absence of echocardiographic follow-up in $5.2 \%$ of the study patients. The fact that none of these patients had developed any symptoms suggestive of CTEPH over a 2-year period or before they died is reassuring. Furthermore, our study lacked a control group. Hence, we cannot exactly determine to what extent the application of the algorithm would have led to an earlier CTEPH diagnosis and to potential benefits in use of healthcare resources, compared with the usual care setting.

In conclusion, the InShape II algorithm for follow-up after acute PE accurately ruled out CTEPH, while avoiding echocardiograms in $81 \%$ of patients with PE. The algorithm led to a much earlier detection of CTEPH than is common in current routine practice.

\section{Author affiliations}

'Department of Thrombosis and Hemostasis, Leiden Universitair Medisch Centrum, Leiden, The Netherlands

${ }^{2}$ Department of Vascular Medicine, Amsterdam Cardiovascular Sciences, Amsterdam UMC, University of Amsterdam, Amsterdam, The Netherlands

${ }^{3}$ Department of Pulmonology, Haga Teaching Hospital, The Hague, The Netherlands ${ }^{4}$ Department of Pneumology, KU Leuven University Hospitals Leuven, Leuven, Belgium

${ }^{5}$ Department of Internal Medicine and Cardiology, Medical University of Warsaw, Warszawa, Poland

${ }^{6}$ Department of Internal Medicine, Haga Teaching Hospital, The Hague, The Netherlands

${ }^{7}$ Department of Pulmonology, Amsterdam UMC, VU University Medical Centre, Amsterdam, The Netherlands

${ }^{8}$ Department of Cardiovascular Sciences, Centre for Molecular and Vascular Biology, University Hospitals Leuven, Leuven, Belgium

${ }^{9}$ Department of Cardiology, Leiden Universitair Medisch Centrum, Leiden, The Netherlands

${ }^{10}$ Department of Cardiology, Haga Teaching Hospital, The Hague, The Netherlands

Collaborators InShape II study group: Authors: The Netherlands: FA Klok, GJAM Boon, YM Ende-Verhaar, MV Huisman, HW Vliegen, (Leiden University Medical Center, Leiden); ATA Mairuhu, LH El Bouazzaoui, JWJ Vriend (Haga Teaching Hospital, The Hague); S Middeldorp, R Bavalia (Amsterdam UMC, University of Amsterdam, Amsterdam); A Vonk Noordegraaf, D Ruigrok (Amsterdam UMC, VU University Medical Centre, Amsterdam); Poland: P Pruszczyk, O Dzikowska-Diduch, K Kurnicka (Medical University of Warsaw, Warsaw); Belgium: M Delcroix, P Verhamme (University Hospitals Leuven, Leuven). Collaborators: The Netherlands: SV Hendriks, LM van der Pol (Haga Teaching hospital, The Hague and Leiden University Medical Center, Leiden); IM Bistervels, PI Bonta (Amsterdam UMC, University of Amsterdam, Amsterdam); 0 Kamp, MJ Beeke (Amsterdam UMC, VU University Medical Centre, Amsterdam); Poland: M Roik (Medical University of Warsaw, Warsaw).

Contributors GJAMB was responsible for design of the study, data collection, analysis and interpretation, as well as drafting of the manuscript. YME-V was responsible for the design of the study, data collection, analysis and interpretation, as well as drafting of the manuscript. RB was responsible for data collection and critically revised the manuscript for important intellectual content. LHEB was responsible for data collection and critically revised the manuscript for important intellectual content. MD was responsible for design of the study, data collection and critically revised the manuscript for important intellectual content. OD-D was responsible for data collection and critically revised the manuscript for important intellectual content. MVH was responsible for design of the study, data collection, analysis and interpretation, as well as drafting of the manuscript. KK was responsible for data collection and critically revised the manuscript for important intellectual content. ATAM was responsible for design of the study, data collection, and critically revised the manuscript for important intellectual content. SM was responsible for design of the study, data collection and critically revised the manuscript for important intellectual content. PP was responsible for design of the study, data collection and critically revised the manuscript for important intellectual content. DR was responsible for data collection and critically revised the manuscript for important intellectual content. PV was responsible for design of the study, data collection, and critically revised the manuscript for important intellectual content. HWV was responsible for design of the study, data collection and critically revised the manuscript for important intellectual content. AVN was responsible for design of the study, data collection and critically revised the manuscript for important intellectual content. JWJV was responsible for data collection and critically revised the manuscript for important intellectual content. FAK was responsible for design 
of the study, data collection, analysis and interpretation, as well as drafting of the manuscript.

Funding GJAMB en FAK were supported by the Dutch Heart Foundation (2017T064). This work was supported by unrestricted grants from Bayer/Merck Sharp \&Dohme (MSD) and Actelion Pharmaceuticals Ltd.

Competing interests GJAMB was supported by the Dutch Heart Foundation (2017T064). MH reports grants from ZonMW Dutch Healthcare Fund, grants and personal fees from Pfizer-BMS, grants and personal fees from Bayer Health Care, grants and personal fees from Daiichi-Sankyo, grants from Leo Pharma, outside the submitted work. SM reports grants and personal fees from Daiichi Sankyo, grants and personal fees from Bayer, personal fees from BMS-Pfizer, personal fees from Boehringer-Ingelheim, personal fees from Portola, personal fees from AbbVie, outside the submitted work. PV reports grants from Bayer, grants from Boehringer, grants from BMS, grants from Daiichi-Sankyo, grants from Pfizer, grants from Leo-Pharma, grants from Sanofi, grants from Anthos Therapeutics, outside the submitted work. AVN reports grants from Netherlands CardioVascular Research Initiative, grants from Netherlands Organization for Scientific Research, other from Johnson \& Johnson and Ferrer in the past 3 years, non-financial support from member of scientific advisory board of Morphogen-XI, outside the submitted work. FAK reports research grants from Bayer, Bristol-Myers Squibb, Boehringer-Ingelheim, Daiichi-Sankyo, MSD and Actelion, the Dutch Heart foundation (2017T064) and the Dutch Thrombosis association, all outside the submitted work.

Patient consent for publication Not required.

Ethics approval Ethical approval is obtained on 7 January 2016 (NL54450.058.15).

Provenance and peer review Not commissioned; externally peer reviewed. Data availability statement Data are available upon reasonable request.

\section{ORCID iDs}

Gudula J A M Boon http://orcid.org/0000-0003-4532-436X

Yvonne M Ende-Verhaar http://orcid.org/0000-0001-7357-9760

Roisin Bavalia http://orcid.org/0000-0002-1806-1050

Marion Delcroix http://orcid.org/0000-0001-8394-9809

Olga Dzikowska-Diduch http://orcid.org/0000-0002-8132-1660

Menno V Huisman http://orcid.org/0000-0003-1423-5348

Katarzyna Kurnicka http://orcid.org/0000-0001-8278-7924

Albert T A Mairuhu http://orcid.org/0000-0001-8278-7924

Saskia Middeldorp http://orcid.org/0000-0002-1006-6420

Piotr Pruszczyk http://orcid.org/0000-0002-9768-0000

Dieuwertje Ruigrok http://orcid.org/0000-0002-8868-6857

Peter Verhamme http://orcid.org/0000-0001-8698-2858

Hubert W Vliegen http://orcid.org/0000-0002-6181-3377

Anton Vonk Noordegraaf http://orcid.org/0000-0002-4057-758X

Frederikus A Klok http://orcid.org/0000-0001-9961-0754

\section{REFERENCES}

1 Simonneau G, Torbicki A, Dorfmüller P, et al. The pathophysiology of chronic thromboembolic pulmonary hypertension. Eur Respir Rev 2017;26:160112.

2 Delcroix M, Kerr K, Fedullo P. Chronic thromboembolic pulmonary hypertension. epidemiology and risk factors. Ann Am Thorac Soc 2016;13 Suppl 3:S201-6.

3 Kim NH, Delcroix M, Jais X, et al. Chronic thromboembolic pulmonary hypertension. Eur Respir J 2019:53:1801915.

4 Delcroix M, Torbicki A, Gopalan D, et al. ERS statement on chronic thromboembolic pulmonary hypertension. Eur Respir J 2020. doi:10.1183/13993003.02828-2020. [Epub ahead of print: 17 Dec 2020].

5 Huisman MV, Barco S, Cannegieter SC, et al. Pulmonary embolism. Nat Rev Dis Primers 2018;4:18028.

6 Ende-Verhaar YM, Cannegieter SC, Vonk Noordegraaf A, et al. Incidence of chronic thromboembolic pulmonary hypertension after acute pulmonary embolism: a contemporary view of the published literature. Eur Respir J 2017;49:1601792.

7 Ende-Verhaar YM, Huisman MV, Klok FA. To screen or not to screen for chronic thromboembolic pulmonary hypertension after acute pulmonary embolism. Thromb Res 2017;151:1-7.

8 Delcroix M, Lang I, Pepke-Zaba J, et al. Long-Term outcome of patients with chronic thromboembolic pulmonary hypertension: results from an international prospective registry. Circulation 2016;133:859-71.

9 Pepke-Zaba J, Delcroix M, Lang I, et al. Chronic thromboembolic pulmonary hypertension (CTEPH): results from an international prospective registry. Circulation 2011;124:1973-81.

10 Klok FA, Barco S, Konstantinides SV, et al. Determinants of diagnostic delay in chronic thromboembolic pulmonary hypertension: results from the European CTEPH registry. Eur Respir J 2018:52:1801687.
11 Ende-Verhaar YM, van den Hout WB, Bogaard HJ, et al. Healthcare utilization in chronic thromboembolic pulmonary hypertension after acute pulmonary embolism. J Thromb Haemost 2018;16:2168-74.

12 Galiè N, Humbert M, Vachiery J-L, et al. 2015 ESC/ERS guidelines for the diagnosis and treatment of pulmonary hypertension: the joint Task force for the diagnosis and treatment of pulmonary hypertension of the European Society of cardiology (ESC) and the European respiratory Society (ERS): endorsed by: association for European paediatric and congenital cardiology (AEPC), International Society for heart and lung transplantation (ISHLT). Eur Heart J 2016;37:67-119.

13 Boon GJAM, Bogaard HJ, Klok FA. Essential aspects of the follow-up after acute pulmonary embolism: an illustrated review. Res Pract Thromb Haemost 2020;4:958-68.

14 Klok FA, van Kralingen KW, van Dijk APJ, et al. Prospective cardiopulmonary screening program to detect chronic thromboembolic pulmonary hypertension in patients after acute pulmonary embolism. Haematologica 2010;95:970-5.

15 Konstantinides SV, Meyer G, Becattini C, et al. 2019 ESC guidelines for the diagnosis and management of acute pulmonary embolism developed in collaboration with the European respiratory Society (ERS). Eur Heart $J$ 2020;41:543-603.

16 Klok FA, van Kralingen KW, van Dijk APJ, et al. Prevalence and potential determinants of exertional dyspnea after acute pulmonary embolism. Respir Med 2010;104:1744-9.

17 Kahn SR, Akaberi A, Granton JT, et al. Quality of life, dyspnea, and functional exercise capacity following a first episode of pulmonary embolism: results of the ELOPE cohort study. Am J Med 2017;130:990.e9-990.e21.

18 Kahn SR, Hirsch AM, Akaberi A, et al. Functional and exercise limitations after a first episode of pulmonary embolism: results of the ELOPE prospective cohort study. Chest 2017; 151:1058-68.

19 Klok FA, Dzikowska-Diduch O, Kostrubiec M, et al. Derivation of a clinical prediction score for chronic thromboembolic pulmonary hypertension after acute pulmonary embolism. J Thromb Haemost 2016;14:121-8.

20 Klok FA, Surie S, Kempf T, et al. A simple non-invasive diagnostic algorithm for ruling out chronic thromboembolic pulmonary hypertension in patients after acute pulmonary embolism. Thromb Res 2011;128:21-6.

21 Klok FA, Tesche C, Rappold L, et al. External validation of a simple non-invasive algorithm to rule out chronic thromboembolic pulmonary hypertension after acute pulmonary embolism. Thromb Res 2015;135:796-801.

22 Ende-Verhaar YM, Ruigrok D, Bogaard HJ, et al. Sensitivity of a simple noninvasive screening algorithm for chronic thromboembolic pulmonary hypertension after acute pulmonary embolism. TH Open 2018;2:e89-95.

23 Pengo V, Lensing AWA, Prins MH, et al. Incidence of chronic thromboembolic pulmonary hypertension after pulmonary embolism. N Eng/ J Med 2004;350:2257-64.

24 Konstantinides SV, Vicaut E, Danays T, et al. Impact of Thrombolytic Therapy on the Long-Term Outcome of Intermediate-Risk Pulmonary Embolism. J Am Coll Cardiol 2017:69:1536-44

25 Kline JA, Steuerwald MT, Marchick MR, et al. Prospective evaluation of right ventricular function and functional status 6 months after acute submassive pulmonary embolism: frequency of persistent or subsequent elevation in estimated pulmonary artery pressure. Chest 2009;136:1202-10.

26 Vonk-Noordegraaf A, Haddad F, Chin KM, et al. Right heart adaptation to pulmonary arterial hypertension: physiology and pathobiology. J Am Coll Cardiol 2013;62:D22-33

27 Simonneau G, Montani D, Celermajer DS, et al. Haemodynamic definitions and updated clinical classification of pulmonary hypertension. Eur Respir J 2019;53:1801913.

28 Guérin L, Couturaud F, Parent F, et al. Prevalence of chronic thromboembolic pulmonary hypertension after acute pulmonary embolism. prevalence of CTEPH after pulmonary embolism. Thromb Haemost 2014;112:598-605.

29 Ende-Verhaar YM, Meijboom LJ, Kroft LJM, et al. Usefulness of standard computed tomography pulmonary angiography performed for acute pulmonary embolism for identification of chronic thromboembolic pulmonary hypertension: results of the InShape III study. J Heart Lung Transplant 2019:38:731-8.

30 Lorenz G, Saeedan MB, Bullen J, et al. Ct-Based biomarkers for prediction of chronic thromboembolic pulmonary hypertension after an acute pulmonary embolic event. AJR Am J Roentgenol 2020;215:800-6.

31 Remy-Jardin M, Ryerson CJ, Schiebler ML, et al. Imaging of pulmonary hypertension in adults: a position paper from the Fleischner Society. Eur Respir J 2021;57:2004455

32 Ni J-R, Yan P-J, Liu S-D, et al. Diagnostic accuracy of transthoracic echocardiography for pulmonary hypertension: a systematic review and meta-analysis. BMJ Open 2019:9:e033084.

33 Klok FA, van der Hulle T, den Exter PL, et al. The post-PE syndrome: a new concept for chronic complications of pulmonary embolism. Blood Rev 2014;28:221-6. 